\title{
Delirium in the ICU: an overview
}

\author{
Rodrigo Cavallazzi ${ }^{1}$, Mohamed Saad ${ }^{1}$ and Paul E Marik ${ }^{2,3^{*}}$
}

\begin{abstract}
Delirium is characterized by a disturbance of consciousness with accompanying change in cognition. Delirium typically manifests as a constellation of symptoms with an acute onset and a fluctuating course. Delirium is extremely common in the intensive care unit (ICU) especially amongst mechanically ventilated patients. Three subtypes have been recognized: hyperactive, hypoactive, and mixed. Delirium is frequently undiagnosed unless specific diagnostic instruments are used. The CAM-ICU is the most widely studied and validated diagnostic instrument. However, the accuracy of this tool may be less than ideal without adequate training of the providers applying it. The presence of delirium has important prognostic implications; in mechanically ventilated patients it is associated with a 2.5-fold increase in short-term mortality and a 3.2-fold increase in 6-month mortality. Nonpharmacological approaches, such as physical and occupational therapy, decrease the duration of delirium and should be encouraged. Pharmacological treatment for delirium traditionally includes haloperidol; however, more data for haloperidol are needed given the paucity of placebo-controlled trials testing its efficacy to treat delirium in the ICU. Second-generation antipsychotics have emerged as an alternative for the treatment of delirium, and they may have a better safety profile. Dexmedetomidine may prove to be a valuable adjunctive agent for patients with delirium in the ICU.
\end{abstract}

Keywords: Delirium, Critical illness, Coma, Sedatives, Antipsychotics

\section{Definition}

Delirium is a syndrome of several different etiologies characterized by a disturbance of consciousness with accompanying change in cognition. Characteristic features of the syndrome include impaired short-term memory, impaired attention, disorientation, development over a short period of time, and a fluctuating course [1]. Not all described features need to be present for the diagnosis of delirium, and the intensity of the symptoms ranges widely among patients. One of several approaches to classify delirium is to divide it into motoric subtypes. Three subtypes of delirium are recognized based on the pattern of symptoms: hyperactive, hypoactive, and mixed [2]. Physiologically, delirium is characterized by a derangement of cerebral metabolism with cerebral dysfunction and is usually caused by a general medical illness, intoxication, or substance withdrawal $[1,3]$. The syndrome of delirium encompasses a few distinct entities with unique pathophysiology and clinical

\footnotetext{
* Correspondence: marikpe@evms.edu

${ }^{2}$ Division of Pulmonary and Critical Care, Eastern Virginia Medical School, Norfolk VA, USA

${ }^{3}$ Department of Medicine, Eastern Virginia Medical School, 825 Fairfax Avenue, Suite 410, Norfolk, VA 23507, USA

Full list of author information is available at the end of the article
}

manifestations. These include sepsis-associated encephalopathy, alcohol withdrawal syndrome, and hepatic encephalopathy.

\section{Epidemiology}

In a multicenter study, the prevalence of delirium in ICU patients was $32.3 \%$ [4]. In specialized ICUs, the prevalence of delirium may be higher. For instance, a study showed a prevalence of delirium as high as $77 \%$ in ventilated burn patients [5]. The incidence of delirium in the ICU ranges from $45 \%$ to $87 \%$ [6-8]. The incidence appears to vary according to whether the studied population is composed exclusively of mechanically ventilated patients. As an example, a study found an incidence of delirium of only $20 \%$ in nonintubated ICU patients [9], whereas another study found an incidence of $83 \%$ in mechanically ventilated patients [10].

The two most common types of delirium in the ICU are mixed and hypoactive [11]. Hypoactive delirium tends to occur more frequently in older patients compared with other types of delirium and has a worse prognosis. In a study of patients who underwent elective surgery with postoperative ICU admission, the 6-month mortality was $32 \%$

\section{实 Springer}


in patients with hypoactive delirium compared with $8.7 \%$ in those with other types of delirium [12].

\section{Pathophysiology}

Different mechanisms have been proposed to explain the pathophysiology of delirium. However, these mechanisms are not mutually exclusive and it is likely that they often act in concert (Figure 1). One hypothesis postulates that decreased cholinergic activity may lead to delirium [13]. This hypothesis is supported by the observation that anticholinergic medication use is associated with increase in delirium symptoms [14] and that patients with delirium have higher serum anticholinergic activity compared with those without delirium [15].

Acetylcholine down regulates inflammation. Thus, it is not surprising that there is an imbalance between inflammatory and anti-inflammatory mediators in delirium, with increased levels of inflammatory mediators and a blunted anti-inflammatory response [16]. In this light, the role of inflammation and its consequent deranged coagulation has been explored in a recent cohort study of mechanically ventilated ICU patients. In this study, five markers of inflammation and four markers of coagulation were measured in the plasma of patients. After adjustment for potential confounders, including severity of illness, higher plasma concentrations of the inflammatory marker soluble tumor necrosis factor receptor-1, and lower plasma concentrations of the coagulation marker protein $\mathrm{C}$ were associated with increased risk of delirium. However, an unexpected finding was that lower plasma concentrations of matrix metalloproteinase-9, another inflammatory marker, were associated with higher risk of delirium [17]. Another mechanism implicated in the pathophysiology of delirium is overactivity of the dopaminergic system. Clinically, evidence for this comes from case reports associating bupropion, an antidepressant with dopamine and norepinephrine activity, with development of delirium [18]. Furthermore, a genetic basis for increased dopaminergic system-induced delirium has been substantiated by the demonstration that mutant genes leading to lower cerebral dopamine activity are protective against delirium [19].

Both increased serotonergic activity and a relative serotonin deficiency also have been associated with delirium [20]. A high serotonergic state in association with delirium has been classically described in patients with the serotonin syndrome, a condition often emerging from the interaction of medications leading to increased serotonergic effects and that in its most severe form presents with hyperthermia, muscle rigidity, and multiple organ failure [21]. On the other hand, low levels of tryptophan-an amino acid that crosses the blood brain barrier and is a precursor to neurotransmitters serotonin and melatonin-have been associated with delirium after surgery in patients older 50 years [22]. Another study found that either high or very low levels of tryptophan are independently associated with an increased risk of delirium in ICU mechanically ventilated patients [23]. Whereas decreased serotonin activity may be implicated in the development of delirium, it also is possible that the production of other metabolites of tryptophan, such as kynurenine, leads to pathway activity that results in neurotoxins predisposing to delirium [24].

Patients who are more prone to delirium, such as the elderly or those with underlying central nervous system disease, also may have heightened central nervous system response to inflammatory mediators. It appears that these patients may have an increased number of microglial cells, which are primed and can be readily activated in response to a mild stressor [25].

The amino-acid neurotransmitter system has a prominent role in the pathophysiology of alcohol withdrawal syndrome. In particular, chronic alcohol exposure may lead to a decrease in the number of and function of gamma aminobutyric acid receptors and an increase in the $N$-methylD-aspartate receptors. Both mechanisms could predispose patients to alcohol withdrawal syndrome [26,27].

\section{Clinical manifestations}

Delirium typically manifests as a constellation of symptoms with an acute onset and a fluctuating course. These

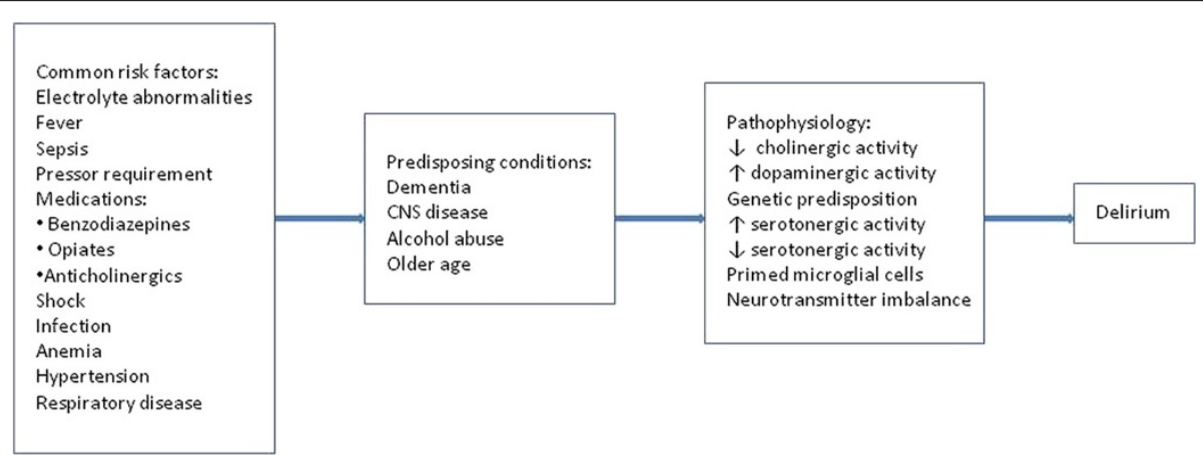

Figure 1 Factors leading to delirium. 
symptoms have been organized into cognitive and behavioral groups. Common cognitive symptoms include disorientation, inability to sustain attention, impaired short-term memory, impaired visuospatial ability, reduced level of consciousness, and perseveration. Common behavioral symptoms include sleep-wake cycle disturbance, irritability, hallucinations, and delusions [28]. The manifestations of delirium can vary widely among patients. Whereas some patients may manifest somnolence and even coma, others appear anxious, disruptive, or combative [29]. Recognition of this symptom variability has led to the classification of delirium into motoric subtypes. One such subtype is hyperactive delirium, of which the manifestations include agitation, hypervigilance, irritability, lack of concentration, and perseveration. Hypoactive delirium manifests as diminished alertness, absence of or slowed speech, hypokinesia, and lethargy. Mixed delirium, as the name implies, includes manifestations of both hyperactive and hypoactive delirium [2].

The clinical manifestations also vary according to the precipitating factors. For instance, patients with bacteremia often present with encephalopathy and declined mental status [30]. Conversely, patients with alcohol withdrawal syndrome present with symptoms of an overactive sympathetic central nervous system [31]. As a consequence, patients with alcohol withdrawal syndrome commonly have agitation, insomnia, tremor, tachycardia, and hypertension [32].

\section{Assessment of delirium}

A number of instruments are available to detect delirium in critically ill patients. The importance of using these instruments lies in that most cases of delirium in the ICU go undetected. Indeed, there is evidence that even when prompted to report delirium, ICU physicians recognize less than one third of delirious critically ill patients when they are not using an instrument to aid in their diagnosis [33]. In a systematic review from 2007, six validated instruments to assess delirium in critically ill patients were identified. These included the Cognitive Test for Delirium, abbreviated Cognitive Test for Delirium, Confusion Assessment Method for the Intensive Care Unit (CAM-ICU), Intensive Care Delirium Screening Checklist, Neelon and Champagne Confusion Scale, and the Delirium Detection Score [34]. Another instrument to detect delirium is the Nursing Delirium Screening Scale, of which the validity and reliability were assessed in the ICU [35]. Table 1 summarizes these diagnostic instruments [8,36-40].

The most extensively studied instrument is the CAMICU, which was validated to assess delirium at the bedside in nonverbal ventilated ICU patients [41]. Using a structured format, this tool evaluates four features, namely, acute onset or fluctuating course, inattention, disorganized thinking, and altered level of consciousness. When administered by bedside nurses with no formal psychiatric training, the CAM-ICU demonstrated high accuracy (sensitivity of $93 \%$ to $100 \%$ and specificity of $98 \%$ to $100 \%)$ and interrater reliability $(\mathrm{K}=0.96)$ in a single-center study [10]. In another study, the CAM-ICU was systematically applied by bedside nurses in the ICU during an implementation process that involved training of the nurses. The agreement between the assessment from bedside nurses and a research staff rater was low at baseline but very high during the implementation process [42]. However, subsequent studies have shown that the CAM-ICU has a more modest sensitivity ranging from $64 \%$ to $81 \%$, whereas the specificity remains high ranging from $88 \%$ to $98 \%$ [33,43,44]. In a more recent study, CAM-ICU had a high specificity (98\%) but a rather low sensitivity (47\%) [45]. The contrast between the latter study and others $[42,46]$ may stem from different implementation processes, that is, different approaches to training and education of providers applying the tool.

Two studies have compared different instruments for detection of delirium in critically ill patients $[33,43]$. In one study, CAM-ICU was prospectively compared with the Intensive Care Delirium Screening Checklist in 126 patients. CAM-ICU showed superior sensitivity (64\% vs. $43 \%$ ) but lower specificity ( $88 \%$ vs. 95\%) [33]. In another study, the accuracy of three instruments (CAM-ICU, Nursing Delirium Screening Scale, and Delirium Detection Score) was compared in a prospective study of 156 patients. Although the sensitivities of CAM-ICU and the Nursing Delirium Screening Scale were similar (81\% for CAM-ICU; 83\% for Nursing Delirium Screening Scale), the CAM-ICU showed superior specificity (96\% vs. 81\%). The Delirium Detection Score showed a sensitivity of $30 \%$ and a specificity of $91 \%$ [43].

The above-mentioned instruments are our best tools for the early detection of delirium in the ICU, but their widespread application has some limitations. First, studies show quite different sensitivities for the same instrument, particularly the CAM-ICU. The difference in sensitivities may be explained by heterogeneity in the patient populations included in the studies but more notably by differential level of training and experience among the assessors in the studies. Thus, it is difficult to establish how accurate these instruments are without adequate training, but it is reasonable to infer that a substantial proportion of critically ill patients with delirium will remain undiagnosed if these instruments are applied by inexperienced or nontrained health care providers. In support of this notion, two recent systematic reviews pooled several studies evaluating the accuracy of CAM-ICU $[47,48]$. The majority of the studies included in the systematic reviews showed that the CAMICU is a highly accurate instrument for the diagnosis of delirium in the ICU. However, in the only study that was performed in a nonresearch setting, most patients with delirium were not detected by CAM-ICU $[45,47]$. 
Table 1 Instruments for the diagnosis of delirium in the ICU

\begin{tabular}{ll}
\hline Instrument & Assessment features \\
\hline $\begin{array}{l}\text { Abbreviated } \\
\text { Cognitive Test } \\
\text { for delirium }\end{array}$ & $\begin{array}{l}\text { Total score obtained by summing up two } \\
\text { content scores: attention (range 0-14) and } \\
\text { [36] }\end{array}$ \\
\hline $\begin{array}{ll}\text { Confusion } & \text { The instrument assesses four features: 1) acute } \\
\text { Assessment } & \text { onset of mental status changes or fluctuating } \\
\text { Method for } & \text { course; 2) inattention; 3) disorganized thinking; } \\
\text { the ICU [8] } & \text { 4) altered level of consciousness }\end{array}$
\end{tabular}

Assessment method Diagnosis

Memory is assessed by recognition of pictured $<11$

objects. Attention is assessed using the visual memory span subtest of the Wechsler Memory Scale-Revised.

Feature 1: assess for acute change in mental status, fluctuating behavior or serial Glasgow Coma Score or sedation ratings over 24 hours. Feature 2: assess using picture recognition or random letter test. Feature 3: assess by asking the patient to hold up a certain number of fingers. Feature 4: rate level of consciousness from alert to coma.

Intensive Care Checklist of eight items: altered level of Delirium consciousness, inattention, disorientation, Screening Checklist [37] hallucination or delusion, psychomotor agitation or retardation, inappropriate mood or speech, sleep/wake cycle disturbance, and symptom fluctuation. The presence of each item of the scale is attributed one point.

Neelon and The scale is divided into three subscales: 1) Champagne information processing (attention, processing Confusion and orientation); 2) behavior (appearance, Scale [38] motor and verbal behavior); and 3) physiological condition (vital function, oxygen saturation, and urinary incontinence). The subscales contain a total of nine items. The score ranges from 0 through 30 . Each item is scored according to the severity of the symptom.

Delirium Eight criteria: agitation, anxiety, hallucination,

Detection

Score [39] orientation, seizures, tremor, paroxysmal sweating, and altered sleep-wake rhythm. Each criterion has four severity levels and accounts for $0,1,4$, or 7 points depending on severity of the symptom.

Nursing This scale contains five items: disorientation

Delirium

Screening

Scale [40]
The scale is completed based on information collected from the entire shift. Items scored in a structured way with definitions available for every item.

\section{Information based on observations by nurses at bedside. Items scored in a structured way with definitions available for every item.}

Features 1 or 2 are positive, along with either Feature 2 or Feature 4

$\geq 4$

iagnosis
Moderate to severe delirium (019); mild to early delirium (20-24); at high risk for delirium (25-26); no delirium (27-30)
Assessment performed during each shift by $\quad>7$ the treating physician and nurse who used a

form with the items and definitions. The highest score in each shift was recorded. Items scored in a structured way with definitions available for every item.

Assessment performed per shift by bedside $>1$ nurses.
This scale contains five items: disorientation
(verbal or behavioral manifestation of not being oriented to time or place or

misperceiving persons in the environment); inappropriate behavior (behavior inappropriate to place and/or for the person, such as pulling at tubes or dressings, attempting to get out of bed when that is contraindicated, and the like); inappropriate communication (communication inappropriate to place and/or for the person, such as incoherence, noncommunicativeness, nonsensical or unintelligible speech); illusions/ hallucinations (seeing or hearing things that are not there or distortions of visual objects); and psychomotor retardation (delayed responsiveness or few or no spontaneous actions/words). Symptoms are rated from 0 to 2 based on the presence and intensity of each symptom. Total score is obtained from the addition of the symptom ratings. Maximal score is 10 .
Whether these instruments can be feasibly implemented in busy nonacademic ICUs is an important issue. Furthermore, it is not well established that the systematic application of these instruments influences the outcomes of critically ill patients. However, there is evidence that when delirium screening is applied as part of a broader protocol initiative that includes active management of sedatives and analgesics as well as nonpharmacological measures, such as music and reassurance, several clinical benefits may ensue, such as shorter duration of mechanical ventilation, lower ICU and hospital stay, and lower 30-day mortality [49]. The protocol also is associated with cost savings [50]. 


\section{Biomarkers}

Several biomarkers have been associated with delirium. Serum anticholinergic activity is enhanced in patients with delirium, and the number of symptoms of delirium increases with higher serum anticholinergic activity level [15]. The S100B protein is an indicator of glial activation and/or death; thus, it is a nonspecific marker of brain injury [51] The S100B protein has been shown to be elevated in patients with delirium [52]. Recently, emphasis has been given to the study of inflammatory biomarkers for the prediction of delirium. For instance, McGrane et al. evaluated 87 critically ill patients in a study; the majority of them had sepsis upon admission to the ICU. They found that higher baseline levels of procalcitonin or C-reactive protein were associated with more days with delirium [53]. Other investigators have found that the profile of increased inflammatory biomarkers changes in critically ill patients with delirium according to the presence or absence of clinical evidence of inflammation (infection or systemic inflammatory response syndrome) [54]. Additional serum biomarkers shown to be elevated in patients with delirium include brain-derived neurotrophic factor, neuron-specific enolase, interleukins, and cortisol $[55,56]$. Whereas the use of biomarkers for delirium is promising, because they can provide diagnostic and prognostic information, more validation studies are necessary before they can be applied in clinical practice.

\section{Risk factors for delirium}

In a study of non-ICU patients who underwent hip fracture repair, older age and male sex have been associated with an increased and independent risk of delirium [57]. A systematic review that included six observational studies evaluated risk factors for delirium by multivariate analysis. Twenty-five risk factors were significantly associated with delirium, and among those four were recognized as predisposing to delirium: respiratory disease, older age, alcohol abuse, and dementia. Twenty-one risk factors were considered precipitating, because they were related the patient's underlying disease; some of these included electrolyte abnormalities, fever, pressor requirement, increasing opiate dose, and metabolic acidosis [58]. Medications are an important risk factor for delirium, especially in the elderly. Classes of medications commonly associated with delirium include anticholinergic agents, benzodiazepines, and opiates [59]. In the ICU, benzodiazepines appear to have a more prominent role in the development of delirium [60].

\section{Prognosis}

Ely et al. evaluated the effect of delirium on 6-month mortality and length of hospital stay among 224 critically patients receiving mechanical ventilation in a prospective cohort study. Delirium was assessed daily by study nurses with the use of CAM-ICU. After adjusting for clinically relevant variables, including age, severity of illness, comorbid conditions, and use of sedatives and analgesic medications, delirium remained associated with a 3.2-fold increase in 6-month mortality and a 2 -fold increase in hospital stay duration [61]. Outcomes of critically ill patients are influenced not only by the presence of delirium but also the duration of it. In a multicenter study, 354 mechanically ventilated patients had daily assessment for delirium with the use of CAM-ICU. After adjustment for age, severity of disease and other covariates, delirium was associated with a 2.5 -fold increase in short-term mortality, and there was a dose-response increase in mortality with increasing duration of delirium. Patients who had delirium for 1 day had $14.5 \%$ all-cause 30-day mortality, whereas the figure was 39\% for those with 3 days or more of delirium [62]. In another cohort study, 304 patients admitted to a single ICU were evaluated daily with use of CAM-ICU. After adjustment for age, severity of illness, and other covariates, every additional day of delirium in the ICU was associated with a $10 \%$ increase in the hazard of death within 1 year post ICU admission [63]. Delirium in the ICU also is associated with more mechanical ventilation days, longer ICU stay, and longer hospital stay [64]. In patients whose symptoms do not fulfill criteria for a formal diagnosis of delirium, the presence of psychomotor agitation - an individual manifestation of delirium-is associated with increased risk for death after adjustment for Acute Physiology and Chronic Health Evaluation Score (APACHE), age, and the presence of coma [65].

In addition to leading to an increase in hospital stay and mortality, delirium is associated with long-term cognitive impairment. For instance, in a cohort study of 77 patients who underwent mechanical ventilation, more than $70 \%$ of them had cognitive impairment at 1 year follow-up. Increasing duration of delirium was independently associated with cognitive impairment after adjustment for several covariates, including education and preexisting cognitive function [66]. In another cohort study of 1,292 ICU survivors, quality of life questionnaires were sent to patients 18 months after ICU discharge. The study had an overall response rate of $71 \%$. Although there was no statistically significant difference in quality of life between patients with delirium and those without delirium, more pronounced cognitive failure as determined by self-reported cognitive failure questionnaire was found in patients with delirium after adjustment for covariates [67].

\section{Nonpharmacological therapy}

Nonpharmacological therapies have an important role in both the prevention and treatment of delirium. As an example, a study in 852 elderly patients admitted to a hospital showed that an intervention strategy against delirium led to a $40 \%$ decrease in the odds of developing 
delirium. The strategy comprised protocols that targeted risk factors for delirium, such as dehydration, immobility, sleep deprivation, visual impairment, cognitive impairment, and hearing impairment [68]. Although this study was performed in non-ICU patients, it is reasonable to infer that components of the intervention also are effective in critically ill patients. In this light, other authors have emphasized the importance of environmental factors in the risk of developing delirium in the ICU, and some strategies have been proposed to mitigate the impact of delirium. These include noise reduction, natural light exposure at daytime, minimization of artificial light exposure at nighttime, ambient temperature optimization, and improved communication [69].

Noise in the ICU is known to disturb patients' sleep [70]. Furthermore, it has been suggested that a disturbed sleep may influence the risk of delirium. The impact of noise on the quality of sleep and thus on the risk of delirium has been illustrated in a recent clinical trial that demonstrated that the use of earplugs at nighttime leads to better sleep and less confusion [71]. Limiting the exposure to sedatives also may have beneficial effects on the risk of delirium. A randomized, clinical trial showed that protocolized daily interruption of sedatives associated with spontaneous breathing trials leads to significantly shorter duration of coma in mechanically ventilated patients but no significant change in delirium in the assessable patients [72]. The addition of physical and occupational therapy to daily interruption of sedation leads to shorter duration of delirium and better functional status in mechanically ventilated patients [73]. Figure 2 presents a proposed strategy for the initial management of patients with delirium in the ICU.

\section{Pharmacological therapy}

\section{Sedatives}

Sedatives have the potential to promote delirium [74]. In an observational study, lorazepam was an independent and statistically significant risk factor for development of delirium whereas other sedatives, such as propofol and opiates, had no statistically significant association with delirium [60]. In a randomized, double-blind trial, 30 hospitalized AIDS patients with delirium were assigned to treatment with haloperidol, chlorpromazine, or lorazepam. Treatment with haloperidol or chlorpromazine resulted in significant improvement in the symptoms of delirium and low prevalence of extrapyramidal side effects. Patients

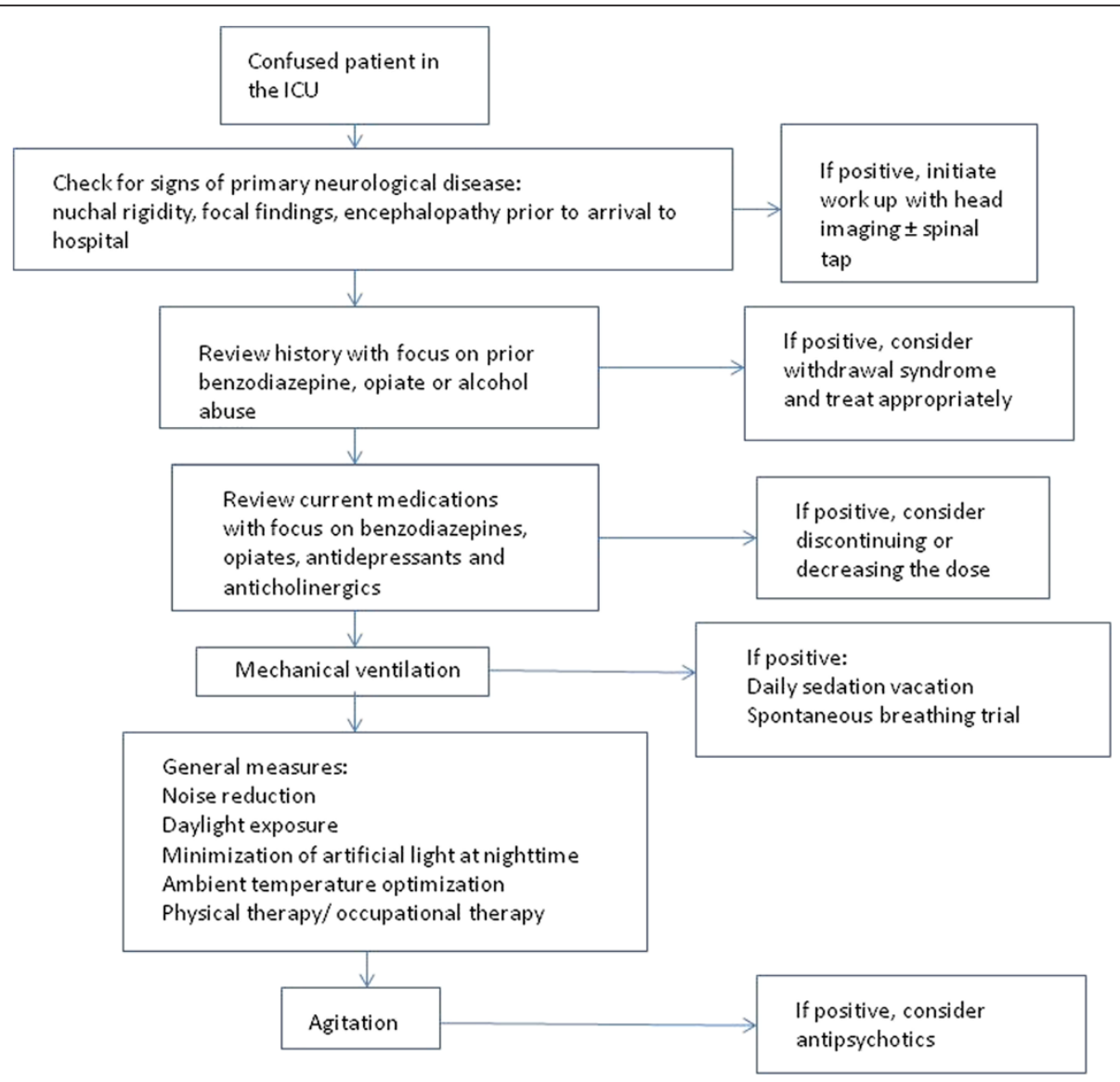

Figure 2 Proposed strategy for the initial management of patients with delirium in the ICU. 
treated with lorazepam had no improvement in delirium and developed treatment-limiting adverse events [75]. Thus, benzodiazepines are generally avoided for the treatment of delirium in hospitalized patients. In fact, because benzodiazepines are an important risk factor for delirium in critically ill patients, limiting their use may decrease the overall incidence of delirium in the ICU. It should be noted, however, that in patients with alcohol withdrawal syndrome, benzodiazepines are the recommended therapy [76]. Furthermore, benzodiazepines should not be abruptly discontinued in patients with benzodiazepine dependence [27].

Dexmedetomidine is a highly selective $\alpha 2$-adrenergic receptor agonist that provides analgesia and "cooperative sedation" without important effects on respiratory status $[77,78]$. It may be a suitable sedative agent for mechanically ventilated patients with delirium or agitation in whom extubation is being considered, a group for which there is little data. A meta-analysis of clinical trials that included nonelective critically ill patients or patients after high-risk elective surgery showed that dexmedetomidine led to a modest reduction in length of ICU stay ( -0.48 days; $95 \%$ CI -0.18 to -0.78 days; $P=0.002$ ) but no significant difference in delirium, mortality, and length of hospital stay. The review was weighed on by studies that included patients who underwent high-risk elective surgery. In addition, the meta-analysis was limited by significant heterogeneity among the included studies, but one important finding was that the use of both a loading dose and a high maintenance dose of dexmedetomidine led to a significantly increased risk of bradycardia (5.8\% vs. $0.4 \% ; P=0.007$ ) [78].

Dexmedetomidine appears to be particularly effective to decrease the risk of delirium compared with benzodiazepines in mechanically ventilated ICU patients. Compared with lorazepam, dexmedetomidine led to a statistically significant increase in days alive without delirium or coma (median 7 vs. $3 ; P=0.1$ ) in a randomized, controlled trial of 106 patients [79]. More recently, Jakob et al. published the results of two clinical trials; one compared dexmedetomidine with midazolam and the other dexmedetomidine with propofol. Although there was no change in length of ICU and hospital stay, those who received dexmedetomidine were more able to arouse, cooperate, and communicate their pain. Dexmedetomidine also led to a reduction in duration of mechanical ventilation compared with midazolam but not compared with propofol. Importantly, dexmedetomidine led to more bradycardia and hypotension compared with midazolam and more first-degree atrioventricular block compared with propofol [80]. Furthermore, there have been reports of patients receiving dexmedetomidine who developed bradycardia and subsequently pulseless electrical activity $[81,82]$. Thus, caution should be exercised in the elderly, patients with underlying heart disease, and those who develop bradycardia while receiving dexmedetomidine.

\section{Antipsychotics}

The first-generation antipsychotic haloperidol has been used traditionally for treatment of delirium. Indeed, the 2002 clinical practice guidelines on sedatives recommend haloperidol as the agent of choice for the treatment of delirium [74]. There also is evidence that haloperidol may be beneficial in preventing delirium in a select group of ICU patients [83]. Patients taking haloperidol should have electrocardiographic monitoring for QT interval prolongation and arrhythmias. In the critical care setting, haloperidol is usually given as an intermittent intravenous injection [74]. More recently, there have been studies that evaluated the efficacy of secondgeneration (atypical) antipsychotic medications in ICU patients (Table 2) [84-87].

\section{Haloperidol for prevention of delirium in the ICU}

In a randomized, double-blind trial from two centers, the effect on delirium prevention of intravenous haloperidol $(0.5 \mathrm{mg}$ followed by an infusion at $0.1 \mathrm{mg} / \mathrm{h}$ over 12 hours) was compared with placebo in 457 patients older than 65 years who were admitted to the ICU after noncardiac surgery. Haloperidol led to a significant decrease in the incidence of delirium within the first 7 days after surgery $(15.3 \%$ vs. $23.2 \% ; P=0.031)$ and a decrease in length of ICU stay ( $21.3 \mathrm{~h}$ vs. $23 \mathrm{~h} ; P=0.024)$. Although haloperidol was associated with lower 28-day mortality, this was not statistically significant $(0.9 \%$ vs. $2.6 \% ; P=0.175)$ [83]. That the patients included in this study were not so ill (as determined by their mean APACHE II score $<9$ ) is a potential drawback of this study. Another limitation is the absence of an outcome determining the patients' functionality, such as ability to return to independent living [88].

\section{Comparison of haloperidol with second- generation (atypical) antipsychotic medications}

In a clinical trial that included 73 ICU patients, oral haloperidol was compared with olanzapine for the treatment of delirium. There was no difference in reduction in delirium severity between the groups; however, 13\% of the patients who received haloperidol developed mild extrapyramidal symptoms, whereas none of the patients in the olanzapine group had these side effects. The study design was limited by inadequate randomization method, small sample size, and lack of blinding from the treating physician and nurses. In addition, the study had no placebo group [87].

A clinical trial, including 101 patients on mechanical ventilation with abnormal level of consciousness, found no difference in number of days alive without delirium 
Table 2 Clinical trials evaluating antipsychotics in critically ill patients with delirium.

\begin{tabular}{|c|c|c|c|c|c|c|c|}
\hline $\begin{array}{l}\text { Author, } \\
\text { year }\end{array}$ & $\begin{array}{l}\text { No. of } \\
\text { patients }\end{array}$ & Inclusion criteria & Interventions & Blinding & Randomization & $\begin{array}{l}\text { Primary } \\
\text { endpoint }\end{array}$ & Results \\
\hline $\begin{array}{l}\text { Reade } \\
{[84]} \\
2009\end{array}$ & 20 & $\begin{array}{l}\text { Mechanical } \\
\text { ventilation, inability } \\
\text { to extubate } \\
\text { because of } \\
\text { agitation }\end{array}$ & $\begin{array}{l}\text { Dexmedetomidine 0.2-0.7 } \\
\mathrm{mcg} / \mathrm{kg} / \mathrm{h} \text { (loading dose } \\
\text { was optional) Haloperidol } \\
0.5-2 \mathrm{mg} / \mathrm{h} \text { (loading dose } \\
\text { was optional) }\end{array}$ & No & $\begin{array}{l}\text { Computer- } \\
\text { generated } \\
\text { random } \\
\text { sequence }\end{array}$ & $\begin{array}{l}\text { Time from } \\
\text { commencement } \\
\text { of study drug to } \\
\text { extubation }\end{array}$ & $\begin{array}{l}\text { Patients on } \\
\text { dexmedetomidine were } \\
\text { extubated sooner than those } \\
\text { on haloperidol: } 9.9 \text { (IQR 7.3- } \\
\text { 24) vs. } 42.5 \text { (IQR 23.2-117.8) } \\
\text { hours, } P=0.016 \text {. }\end{array}$ \\
\hline $\begin{array}{l}\text { Girard } \\
{[85]} \\
2010\end{array}$ & 101 & $\begin{array}{l}\text { Mechanical } \\
\text { ventilation, } \\
\text { abnormal level of } \\
\text { consciousness, } \\
\text { receipt of sedative } \\
\text { or analgesic } \\
\text { medications }\end{array}$ & $\begin{array}{l}\text { Haloperidol } 5 \mathrm{mg} \\
\text { Ziprasidone } 40 \mathrm{mg} \\
\text { placebo. Second dose } \\
\text { administered } 12 \text { hours } \\
\text { after the first if QT < } 500 \\
\text { msec; then every } 6 \text { hours. }\end{array}$ & Yes & $\begin{array}{l}\text { Computer- } \\
\text { generated, } \\
\text { permuted-block } \\
\text { randomization } \\
\text { scheme }\end{array}$ & $\begin{array}{l}\text { Number of days } \\
\text { alive without } \\
\text { delirium or coma }\end{array}$ & $\begin{array}{l}\text { No significant difference in } \\
\text { number of days alive without } \\
\text { delirium or coma. } P=0.66 \text {. } \\
\text { Haloperidol: } 14 \text { (IQR 6-18) } \\
\text { days Ziprasidone: } 15 \text { (IQR 9.1- } \\
\text { 18) days Placebo: } 12.5 \text { (IQR } \\
\text { 1.2-17.2) days }\end{array}$ \\
\hline $\begin{array}{l}\text { Devlin } \\
{[86]} \\
2010\end{array}$ & 36 & $\begin{array}{l}\text { ICU patients with } \\
\text { delirium and an } \\
\text { order for as-needed } \\
\text { haloperidol }\end{array}$ & $\begin{array}{l}\text { Quetiapine } 50 \text { mg every } \\
12 \text { hours titrated upwards } \\
\text { on a daily basis if } \\
\text { haloperidol was needed. } \\
\text { Placebo. }\end{array}$ & Yes & $\begin{array}{l}\text { Computer- } \\
\text { generated } \\
\text { random } \\
\text { sequence }\end{array}$ & $\begin{array}{l}\text { Time to first } \\
\text { resolution of } \\
\text { delirium }\end{array}$ & $\begin{array}{l}\text { Time to first resolution was } \\
\text { shorter with Quetiapine } \\
\text { therapy than with placebo, } P \\
=0.001 \text {. Quetiapine: } 1 \text { (IQR } \\
0.5-3 \text { ) days Placebo: } 4.5 \text { (IQR } \\
\text { 2-7) days }\end{array}$ \\
\hline $\begin{array}{l}\text { Skrobik } \\
{[87]} \\
2004\end{array}$ & 73 & $\begin{array}{l}\text { ICU patients with } \\
\text { delirium }\end{array}$ & $\begin{array}{l}\text { Haloperidol } 2.5-5 \mathrm{mg} \\
\text { every } 8 \text { hours Olanzapine } \\
5 \text { mg daily }\end{array}$ & $\begin{array}{l}\text { Only } \\
\text { those } \\
\text { assessing } \\
\text { outcomes }\end{array}$ & $\begin{array}{l}\text { Even/odds day } \\
\text { basis }\end{array}$ & Not specified & $\begin{array}{l}\text { No difference in delirium } \\
\text { index scores, } P=0.83 \text {. No } \\
\text { difference in benzodiazepine } \\
\text { use, } P=0.9 \text {. }\end{array}$ \\
\hline
\end{tabular}

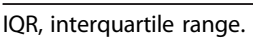

or coma in patients treated with haloperidol, ziprasidone, or placebo. There was no statistically significant difference in extrapyramidal symptoms among the three groups of patients. Limitations of this study included a small sample size and the large proportion of patients (42\%) in the placebo group who received open-label haloperidol [85].

\section{Comparison of haloperidol with dexmedetomidine}

A randomized, open-label trial compared haloperidol with dexmedetomidine in 20 patients with agitated delirium in the ICU. The ICU length of stay was significantly decreased by 5 days in those who received dexmedetomidine. Limitations of this study included lack of blinding and the small sample size [84].

\section{Comparison of second-generation (atypical) antipsychotic medications with placebo}

A randomized, double-blind trial compared quetiapine with placebo in 36 critically ill patients with delirium. All patients were allowed to receive intravenous haloperidol. The time to resolution of delirium was significantly shorter with quetiapine therapy than with placebo; the decrease was by 3.5 days $(P=0.001)$. This study was limited by small sample size, performance of multiple statistical analyses (which increases the odds of type 1 error), and the low enrollment rate, which is the result of stringent inclusion criteria [86].
Final considerations on the use of antipsychotics for treating and preventing delirium in the ICU

In summary, the evidence for use of antipsychotics for treating delirium in the ICU is weak. The studies assessing antipsychotics in the ICU have several limitations as pointed out above. The scarcity of data calls for welldesigned and powered clinical trials. While we wait for those, and in the absence of other effective pharmacological options for the treatment of delirium in the ICU, it is our opinion that antipsychotics can be judiciously used in ICU patients with delirium, particularly in those with agitation.

The data on haloperidol as a prophylactic agent against delirium in the elderly admitted to the ICU after surgery appears promising. However, more studies are needed before haloperidol can be used routinely as a prophylactic agent in this patient population.

\section{Conclusions}

Delirium is common in ICU patients but often goes undetected. Different instruments have been designed to help in the identification of patients with delirium. Whether the implementation of these instruments leads to better outcomes is not fully established. Nonpharmacological approaches, such as physical and occupational therapy, decrease the duration of delirium and should be encouraged. Pharmacological treatment for delirium traditionally includes haloperidol. Second-generation antipsychotics have emerged as an alternative for the treatment of delirium, and they may have a better safety 
profile. However, to date the studies evaluating these medications have been limited by small sample size. More powered clinical trials are needed to establish the first-line pharmacological treatment for delirium.

\section{Abbreviations \\ ICU: Intensive Care Unit; CAM-ICU: Confusion Assessment Method for the Intensive Care Unit.}

\section{Competing interest}

The authors have no conflict of interest nor any real or perceived financial interest in any product mentioned in this paper.

\section{Authors' contributions}

All three authors contributed to writing this manuscript and have reviewed and approved the final version for publication.

\section{Author details}

'Division of Pulmonary, Critical Care, Sleep Disorders University of Louisville, Louisville KY, USA. ${ }^{2}$ Division of Pulmonary and Critical Care, Eastern Virginia Medical School, Norfolk VA, USA. ${ }^{3}$ Department of Medicine, Eastern Virginia Medical School, 825 Fairfax Avenue, Suite 410, Norfolk, VA 23507, USA.

Received: 21 June 2012 Accepted: 6 November 2012

Published: 27 December 2012

\section{References}

1. Anonymous Diagnostic and Statistical Manual of Mental Disorders. 4th edition. Washington, DC: American Psychiatric Association; 2000.

2. Liptzin B, Levkoff SE: An empirical study of delirium subtypes. Br J Psychiatry 1992, 161:843-845.

3. Engel GL, Romano J: Delirium, a syndrome of cerebral insufficiency. 1959. J Neuropsychiatry Clin Neurosci 2004, 16(4):526-538.

4. Salluh J, Soares M, Teles JM, Ceraso D, Raimondi N, Nava VS, Blasquez P, Ugarte S, Ibanez-Guzman C, Centeno JV, Laca M, Grecco G, Jimenez E, AriasRivera S, Duenas C, Rocha MG, Delirium Epidemiology in Critical Care Study Group: Delirium epidemiology in critical care (DECCA): an international study. Crit Care 2010, 14(6):R210.

5. Agarwal V, O'Neill PJ, Cotton BA, Pun BT, Haney S, Thompson J, Kassebaum N, Shintani A, Guy J, Ely EW, Pandharipande P: Prevalence and risk factors for development of delirium in burn intensive care unit patients. J Burn Care Res 2010, 31(5):706-715.

6. Roberts B, Rickard CM, Rajbhandari D, Turner G, Clarke J, Hill D, Tauschke C, Chaboyer W, Parsons R: Multicentre study of delirium in ICU patients using a simple screening tool. Aust Crit Care 2005, 18(1):6. 8-9, 11-14 passim.

7. Thomason JW, Shintani A, Peterson JF, Pun BT, Jackson JC, Ely EW: Intensive care unit delirium is an independent predictor of longer hospital stay: a prospective analysis of 261 non-ventilated patients. Crit Care 2005, 9(4):R375-R381.

8. Ely EW, Margolin R, Francis J, May L, Truman B, Dittus R, Speroff T, Gautam S, Bernard GR, Inouye SK: Evaluation of delirium in critically ill patients: validation of the Confusion Assessment Method for the Intensive Care Unit (CAM-ICU). Crit Care Med 2001, 29(7):1370-1379.

9. Van Rompaey B, Schuurmans MJ, Shortridge-Baggett LM, Truijen S, Elseviers $M$, Bossaert L: A comparison of the CAM-ICU and the NEECHAM Confusion Scale in intensive care delirium assessment: an observational study in non-intubated patients. Crit Care 2008, 12(1):R16.

10. Ely EW, Inouye SK, Bernard GR, Gordon S, Francis J, May L, Truman B, Speroff T, Gautam S, Margolin R, Hart RP, Dittus R: Delirium in mechanically ventilated patients: validity and reliability of the confusion assessment method for the intensive care unit (CAM-ICU). JAMA 2001, 286(21):2703-2710

11. Peterson JF, Pun BT, Dittus RS, Thomason JW, Jackson JC, Shintani AK Ely EW: Delirium and its motoric subtypes: a study of 614 critically ill patients. J Am Geriatr Soc 2006, 54(3):479-484.

12. Robinson TN, Raeburn CD, Tran ZV, Brenner LA, Moss M: Motor subtypes of postoperative delirium in older adults. Arch Surg 2011, 146(3):295-300.

13. Hshieh TT, Fong TG, Marcantonio ER, Inouye SK: Cholinergic deficiency hypothesis in delirium: a synthesis of current evidence. J Gerontol A Biol Sci Med Sci 2008, 63(7):764-772.
14. Han L, McCusker J, Cole M, Abrahamowicz M, Primeau F, Elie M: Use of medications with anticholinergic effect predicts clinical severity of delirium symptoms in older medical inpatients. Arch Intern Med 2001, 161(8):1099-1105.

15. Flacker JM, Cummings V, Mach JR Jr, Bettin K, Kiely DK, Wei J: The association of serum anticholinergic activity with delirium in elderly medical patients. Am J Geriatr Psychiatry 1998, 6(1):31-41.

16. Cerejeira J, Nogueira V, Luis P, Vaz-Serra A, Mukaetova-Ladinska EB: The cholinergic system and inflammation: common pathways in delirium pathophysiology. J Am Geriatr Soc 2012, 60(4):669-675.

17. Girard TD, Ware LB, Bernard GR, Pandharipande PP, Thompson JL, Shintani AK, Jackson JC, Dittus RS, Ely EW: Associations of markers of inflammation and coagulation with delirium during critical illness. Intensive Care Med 2012, 38(12):19651973.

18. Chan CH, Liu HC, Huang MC: Delirium associated with concomitant use of low-dose bupropion sustained release and fluoxetine. J Clin Psychopharmacol 2006, 26(6):677-679.

19. van Munster BC, de Rooij SE, Yazdanpanah M, Tienari PJ, Pitkala KH, Osse RJ, Adamis D, Smit O, van der Steen MS, van Houten M, Rahkonen T, Sulkava R, Laurila JV, Strandberg TE, Tulen JH, Zwang L, MacDonald AJ, Treloar A, Sijbrands EJ, Zwinderman AH, Korevaar JC: The association of the dopamine transporter gene and the dopamine receptor 2 gene with delirium, a meta-analysis. Am J Med Genet B Neuropsychiatr Genet 2010, 153B(2):648-655.

20. Flacker JM, Lipsitz LA: Neural mechanisms of delirium: current hypotheses and evolving concepts. J Gerontol A Biol Sci Med Sci 1999, 54(6):B239-B246.

21. Choudhury M, Hote MP, Verma Y: Serotonin syndrome in a postoperative patient. J Anaesthesiol Clin Pharmacol 2011, 27(2):233-235.

22. Robinson TN, Raeburn CD, Angles EM, Moss M: Low tryptophan levels are associated with postoperative delirium in the elderly. Am J Surg 2008, 196(5):670-674.

23. Pandharipande PP, Morandi A, Adams JR, Girard TD, Thompson JL, Shintani AK, Ely EW: Plasma tryptophan and tyrosine levels are independent risk factors for delirium in critically ill patients. Intensive Care Med 2009, 35(11):1886-1892.

24. Adams Wilson JR, Morandi A, Girard TD, Thompson JL, Boomershine CS, Shintani AK, Ely EW, Pandharipande PP: The association of the kynurenine pathway of tryptophan metabolism with acute brain dysfunction during critical illness*. Crit Care Med 2012, 40(3):835-841.

25. Maclullich AM, Ferguson KJ, Miller T, de Rooij SE, Cunningham C: Unravelling the pathophysiology of delirium: a focus on the role of aberrant stress responses. J Psychosom Res 2008, 65(3):229-238.

26. Davis KM, Wu JY: Role of glutamatergic and GABAergic systems in alcoholism. J Biomed Sci 2001, 8(1):7-19.

27. Kosten TR, O'Connor PG: Management of drug and alcohol withdrawal. N Engl J Med 2003, 348(18):1786-1795.

28. Jain G, Chakrabarti S, Kulhara P: Symptoms of delirium: an exploratory factor analytic study among referred patients. Gen Hosp Psychiatry 2011, 33(4):377-385

29. Dubin WR, Weiss KJ, Zeccardi JA: Organic brain syndrome. The psychiatric imposter. JAMA 1983, 249(1):60-62.

30. Eidelman LA, Putterman D, Putterman C, Sprung CL: The spectrum of septic encephalopathy. Definitions, etiologies, and mortalities. JAMA 1996, 275(6):470-473.

31. Linnoila M, Mefford I, Nutt D, Adinoff B: NIH conference. Alcohol withdrawal and noradrenergic function. Ann Intern Med 1987, 107(6):875-889.

32. Hall W, Zador D: The alcohol withdrawal syndrome. Lancet 1997, 349(9069):1897-1900.

33. van Eijk MM, van Marum RJ, Klijn IA, de Wit N, Kesecioglu J, Slooter AJ: Comparison of delirium assessment tools in a mixed intensive care unit. Crit Care Med 2009, 37(6):1881-1885.

34. Devlin JW, Fong JJ, Fraser GL, Riker RR: Delirium assessment in the critically ill. Intensive Care Med 2007, 33(6):929-940.

35. Gaudreau JD, Gagnon P, Harel F, Tremblay A, Roy MA: Fast, systematic, and continuous delirium assessment in hospitalized patients: the nursing delirium screening scale. J Pain Symptom Manag 2005, 29(4):368-375.

36. Hart RP, Best AM, Sessler CN, Levenson JL: Abbreviated cognitive test for delirium. J Psychosom Res 1997, 43(4):417-423.

37. Bergeron N, Dubois MJ, Dumont M, Dial S, Skrobik Y: Intensive care delirium screening checklist: evaluation of a new screening tool. Intensive Care Med 2001, 27(5):859-864. 
38. Immers HE, Schuurmans MJ, van de Bijl JJ: Recognition of delirium in ICU patients: a diagnostic study of the NEECHAM confusion scale in ICU patients. BMC Nurs 2005, 4:7

39. Otter H, Martin J, Basell K, von Heymann C, Hein OV, Bollert P, Jansch P, Behnisch I, Wernecke KD, Konertz W, Loening S, Blohmer JU, Spies C: Validity and reliability of the DDS for severity of delirium in the ICU. Neurocrit Care 2005, 2(2):150-158.

40. Gaudreau JD, Gagnon P, Harel F, Tremblay A, Roy MA: Fast, systematic, and continuous delirium assessment in hospitalized patients: the nursing delirium screening scale. J Pain Symptom Manage 2005, 29(4):368-375.

41. Wei LA, Fearing MA, Sternberg EJ, Inouye SK: The confusion assessment method: a systematic review of current usage. J Am Geriatr Soc 2008, 56(5):823-830.

42. Pun BT, Gordon SM, Peterson JF, Shintani AK, Jackson JC, Foss J, Harding SD, Bernard GR, Dittus RS, Ely EW: Large-scale implementation of sedation and delirium monitoring in the intensive care unit: a report from two medical centers. Crit Care Med 2005, 33(6):1199-1205.

43. Luetz A, Heymann A, Radtke FM, Chenitir C, Neuhaus U, Nachtigall I, von Dossow V, Marz S, Eggers V, Heinz A, Wernecke KD, Spies CD: Different assessment tools for intensive care unit delirium: which score to use? Crit Care Med 2010, 38(2):409-418.

44. Toro AC, Escobar LM, Franco JG, Diaz-Gomez JL, Munoz JF, Molina F, Bejarano J, Yepes D, Navarro E, Garcia A, Wesley Ely E, Esteban A: Spanish version of the CAM-ICU (Confusion Assessment Method for the Intensive Care Unit). Pilot study of validation. Med Intensiva 2010, 34(1):14-21.

45. van Eijk MM, van den Boogaard M, van Marum RJ, Benner P, Eikelenboom P, Honing ML, van der Hoven B, Horn J, Izaks GJ, Kalf A, Karakus A, Klijn IA, Kuiper MA, de Leeuw FE, de Man T, van der Mast RC, Osse RJ, de Rooij SE, Spronk PE, van der Voort PH, van Gool WA, Slooter AJ: Routine use of the confusion assessment method for the intensive care unit: a multicenter study. Am J Respir Crit Care Med 2011, 184(3):340344.

46. Vasilevskis EE, Morandi A, Boehm L, Pandharipande PP, Girard TD, Jackson JC, Thompson JL, Shintani A, Gordon SM, Pun BT, Wesley Ely E: Delirium and sedation recognition using validated instruments: reliability of bedside intensive care unit nursing assessments from 2007 to 2010. J Am Geriatr Soc 2011, 59(Suppl 2):S249-S255.

47. Neto AS, Nassar AP Jr, Cardoso SO, Manetta JA, Pereira VG, Esposito DC, Damasceno MC, Slooter AJ: Delirium screening in critically ill patients: a systematic review and meta-analysis. Crit Care Med 2012, 40(6):1946-1951.

48. Gusmao-Flores D, Figueira Salluh Jl, Chalhub RA, Quarantini LC: The confusion assessment method for the intensive care unit (CAM-ICU) and intensive care delirium screening checklist (ICDSC) for the diagnosis of delirium: a systematic review and meta-analysis of clinical studies. Crit Care 2012, 16(4):R115.

49. Skrobik Y, Ahern S, Leblanc M, Marquis F, Awissi DK, Kavanagh BP: Protocolized intensive care unit management of analgesia, sedation, and delirium improves analgesia and subsyndromal delirium rates. Anesth Analg 2010, 111(2):451-463.

50. Awissi DK, Begin C, Moisan J, Lachaine J, Skrobik Y: I-SAVE study: impact of sedation, analgesia, and delirium protocols evaluated in the intensive care unit: an economic evaluation. Ann Pharmacother 2012, 46(1):21-28.

51. Goncalves CA, Leite MC, Nardin P: Biological and methodological features of the measurement of $\mathrm{S} 100 \mathrm{~B}$, a putative marker of brain injury. Clin Biochem 2008, 41(10-11):755-763.

52. van Munster BC, Korse CM, de Rooij SE, Bonfrer JM, Zwinderman AH, Korevaar JC: Markers of cerebral damage during delirium in elderly patients with hip fracture. BMC Neurol 2009, 9:21.

53. McGrane S, Girard TD, Thompson JL, Shintani AK, Woodworth A, Ely EW, Pandharipande PP: Procalcitonin and C-reactive protein levels at admission as predictors of duration of acute brain dysfunction in critically ill patients. Crit Care 2011, 15(2):R78.

54. van den Boogaard M, Kox M, Quinn KL, van Achterberg T, van der Hoeven $J G$, Schoonhoven L, Pickkers P: Biomarkers associated with delirium in critically ill patients and their relation with long-term subjective cognitive dysfunction; indications for different pathways governing delirium in inflamed and noninflamed patients. Crit Care 2011, 15(6):R297.

55. Grandi C, Tomasi CD, Fernandes K, Stertz L, Kapczinski F, Quevedo J, Dal-Pizzol F, Ritter C: Brain-derived neurotrophic factor and neuronspecific enolase, but not S100beta, levels are associated to the occurrence of delirium in intensive care unit patients. J Crit Care 2011, 26(2):133-137.
56. van Munster BC, Bisschop PH, Zwinderman AH, Korevaar JC, Endert E, Wiersinga WJ, van Oosten HE, Goslings JC, de Rooij SE: Cortisol, interleukins and S100B in delirium in the elderly. Brain Cogn 2010, 74(1):18-23.

57. Lee HB, Mears SC, Rosenberg PB, Leoutsakos JM, Gottschalk A, Sieber FE: Predisposing factors for postoperative delirium after hip fracture repair in individuals with and without dementia. J Am Geriatr Soc 2011, 59(12):2306-2313.

58. Van Rompaey B, Schuurmans MJ, Shortridge-Baggett LM, Truijen S, Bossaert L: Risk factors for intensive care delirium: a systematic review. Intensive Crit Care Nurs 2008, 24(2):98-107.

59. Alagiakrishnan K, Wiens CA: An approach to drug induced delirium in the elderly. Postgrad Med J 2004, 80(945):388-393.

60. Pandharipande P, Shintani A, Peterson J, Pun BT, Wilkinson GR, Dittus RS, Bernard GR, Ely EW: Lorazepam is an independent risk factor for transitioning to delirium in intensive care unit patients. Anesthesiology 2006, 104(1):21-26.

61. Ely EW, Shintani A, Truman B, Speroff T, Gordon SM, Harrell FE Jr, Inouye SK, Bernard GR, Dittus RS: Delirium as a predictor of mortality in mechanically ventilated patients in the intensive care unit. JAMA 2004, 291(14):1753-1762

62. Shehabi Y, Riker RR, Bokesch PM, Wisemandle W, Shintani A, Ely EW SEDCOM (Safety and Efficacy of Dexmedetomidine Compared With Midazolam) Study Group: Delirium duration and mortality in lightly sedated, mechanically ventilated intensive care patients. Crit Care Med 2010, 38(12):2311-2318.

63. Pisani MA, Kong SY, Kasl SV, Murphy TE, Araujo KL, Van Ness PH: Days of delirium are associated with 1-year mortality in an older intensive care unit population. Am J Respir Crit Care Med 2009, 180(11):1092-1097.

64. Lat I, McMillian W, Taylor S, Janzen JM, Papadopoulos S, Korth L, Ehtisham A, Nold J, Agarwal S, Azocar R, Burke P: The impact of delirium on clinical outcomes in mechanically ventilated surgical and trauma patients. Crit Care Med 2009, 37(6):1898-1905.

65. Marquis F, Ouimet S, Riker R, Cossette M, Skrobik Y: Individual delirium symptoms: do they matter? Crit Care Med 2007, 35(11):2533-2537.

66. Girard TD, Jackson JC, Pandharipande PP, Pun BT, Thompson JL, Shintani AK, Gordon SM, Canonico AE, Dittus RS, Bernard GR, Ely EW: Delirium as a predictor of long-term cognitive impairment in survivors of critical illness. Crit Care Med 2010, 38(7):1513-1520.

67. van den Boogaard M, Schoonhoven L, Evers AW, van der Hoeven JG, van Achterberg T, Pickkers P: Delirium in critically ill patients: impact on longterm health-related quality of life and cognitive functioning. Crit Care Med 2012, 40(1):112-118.

68. Inouye SK, Bogardus ST Jr, Charpentier PA, Leo-Summers L, Acampora D, Holford TR, Cooney LM Jr: A multicomponent intervention to prevent delirium in hospitalized older patients. N Engl J Med 1999, 340(9):669-676.

69. Wenham T, Pittard A: Intensive care unit environment. CEACCP 2009, 9.

70. Topf M, Bookman M, Arand D: Effects of critical care unit noise on the subjective quality of sleep. J Adv Nurs 1996, 24(3):545-551.

71. Van Rompaey B, Elseviers MM, Van Drom W, Fromont V, Jorens PG: The effect of earplugs during the night on the onset of delirium and sleep perception: a randomized controlled trial in intensive care patients. Crit Care 2012, 16(3):R73.

72. Girard TD, Kress JP, Fuchs BD, Thomason JW, Schweickert WD, Pun BT, Taichman DB, Dunn JG, Pohlman AS, Kinniry PA, Jackson JC, Canonico AE, Light RW, Shintani AK, Thompson JL, Gordon SM, Hall JB, Dittus RS, Bernard GR, Ely EW: Efficacy and safety of a paired sedation and ventilator weaning protocol for mechanically ventilated patients in intensive care (Awakening and Breathing Controlled trial): a randomised controlled trial. Lancet 2008, 371(9607):126-134.

73. Schweickert WD, Pohlman MC, Pohlman AS, Nigos C, Pawlik AJ, Esbrook CL, Spears L, Miller M, Franczyk M, Deprizio D, Schmidt GA, Bowman A, Barr R, McCallister KE, Hall JB, Kress JP: Early physical and occupational therapy in mechanically ventilated, critically ill patients: a randomised controlled trial. Lancet 2009, 373(9678):1874-1882.

74. Jacobi J, Fraser GL, Coursin DB, Riker RR, Fontaine D, Wittbrodt ET, Chalfin DB, Masica MF, Bjerke HS, Coplin WM, Crippen DW, Fuchs BD, Kelleher RM, Marik PE, Nasraway SA Jr, Murray MJ, Peruzzi WT, Lumb PD, Task Force of the American College of Critical Care Medicine (ACCM) of the Society of Critical Care Medicine (SCCM), American Society of Health-System Pharmacists (ASHP), American College of Chest Physicians: Clinical practice 
guidelines for the sustained use of sedatives and analgesics in the critically ill adult. Crit Care Med 2002, 30(1):119-141.

75. Breitbart W, Marotta R, Platt MM, Weisman H, Derevenco M, Grau C, Corbera K, Raymond S, Lund S, Jacobson P: A double-blind trial of haloperidol, chlorpromazine, and lorazepam in the treatment of delirium in hospitalized AIDS patients. Am J Psychiatry 1996, 153(2):231-237.

76. Mayo-Smith MF: Pharmacological management of alcohol withdrawal. A meta-analysis and evidence-based practice guideline. American Society of Addiction Medicine Working Group on Pharmacological Management of Alcohol Withdrawal. JAMA 1997, 278(2):144-151.

77. Venn RM, Hell J, Grounds RM: Respiratory effects of dexmedetomidine in the surgical patient requiring intensive care. Crit Care 2000, 4(5):302-308

78. Tan JA, Ho KM: Use of dexmedetomidine as a sedative and analgesic agent in critically ill adult patients: a meta-analysis. Intensive Care Med 2010, 36(6):926-939.

79. Pandharipande PP, Pun BT, Herr DL, Maze M, Girard TD, Miller RR, Shintani AK, Thompson JL, Jackson JC, Deppen SA, Stiles RA, Dittus RS, Bernard GR, Ely EW: Effect of sedation with dexmedetomidine vs lorazepam on acute brain dysfunction in mechanically ventilated patients: the MENDS randomized controlled trial. JAMA 2007, 298(22):2644-2653.

80. Jakob SM, Ruokonen E, Grounds RM, Sarapohja T, Garratt C, Pocock SJ, Bratty JR, Takala J, Dexmedetomidine for Long-Term Sedation Investigators: Dexmedetomidine vs midazolam or propofol for sedation during prolonged mechanical ventilation: two randomized controlled trials. JAMA 2012, 307(11):1151-1160.

81. Bharati S, Pal A, Biswas C, Biswas R: Incidence of cardiac arrest increases with the indiscriminate use of dexmedetomidine: a case series and review of published case reports. Acta Anaesthesiol Taiwan 2011, 49(4):165-167.

82. Gerlach AT, Murphy CV: Dexmedetomidine-associated bradycardia progressing to pulseless electrical activity: case report and review of the literature. Pharmacotherapy 2009, 29(12):1492.

83. Wang W, Li HL, Wang DX, Zhu X, Li SL, Yao GQ, Chen KS, Gu XE, Zhu SN: Haloperidol prophylaxis decreases delirium incidence in elderly patients after noncardiac surgery: a randomized controlled trial*. Crit Care Med 2012, 40(3):731-739.

84. Reade MC, O'Sullivan K, Bates S, Goldsmith D, Ainslie WR, Bellomo R: Dexmedetomidine vs. haloperidol in delirious, agitated, intubated patients: a randomised open-label trial. Crit Care 2009, 13(3):R75.

85. Girard TD, Pandharipande PP, Carson SS, Schmidt GA, Wright PE, Canonico AE, Pun BT, Thompson JL, Shintani AK, Meltzer HY, Bernard GR, Dittus RS, Ely EW, MIND Trial Investigators: Feasibility, efficacy, and safety of antipsychotics for intensive care unit delirium: the MIND randomized, placebo-controlled trial. Crit Care Med 2010, 38(2):428-437.

86. Devlin JW, Roberts RJ, Fong JJ, Skrobik Y, Riker RR, Hill NS, Robbins T, Garpestad E: Efficacy and safety of quetiapine in critically ill patients with delirium: a prospective, multicenter, randomized, double-blind, placebocontrolled pilot study. Crit Care Med 2010, 38(2):419-427.

87. Skrobik YK, Bergeron N, Dumont M, Gottfried SB: Olanzapine vs haloperidol: treating delirium in a critical care setting. Intensive Care Med 2004, 30(3):444-449.

88. Reade MC: The largest ever trial demonstrating effectiveness of intensive care unit delirium prophylaxis--we must know more! Crit Care Med 2012, 40(8):2540.

\section{Submit your manuscript to a SpringerOpen ${ }^{\circ}$ journal and benefit from:}

- Convenient online submission

$\checkmark$ Rigorous peer review

- Immediate publication on acceptance

- Open access: articles freely available online

- High visibility within the field

- Retaining the copyright to your article

Submit your next manuscript at $\gg$ springeropen.com 